\title{
The Isoforms of the p53 Protein
}

\author{
Marie P. Khoury and Jean-Christophe Bourdon \\ University of Dundee, Ninewells Hospital, Centre for Oncology and Molecular Medicine, Inserm-European \\ Associated Laboratory, Inserm U858, CR-UK Cell Transformation Research Group, Dundee United Kingdom, \\ and the Unité mixte Inserm U858, Institut de Médecine Moléculaire de Rangueil, Toulouse, France \\ Correspondence: j.bourdon@dundee.ac.uk
}

p53 is a transcription factor with a key role in the maintenance of genetic stability and therefore preventing cancer formation. It belongs to a family of genes composed of $p 53, p 63$, and $p 73$. The $p 63$ and $p 73$ genes have a dual gene structure with an internal promoter in intron-3 and together with alternative splicing, can express 6 and 29 mRNA variants, respectively. Such a complex expression pattern had not been previously described for the $p 53$ gene, which was not consistent with our understanding of the evolution of the p53 gene family. Consequently, we revisited the human $p 53$ gene structure and established that it encodes nine different p53 protein isoforms because of alternative splicing, alternative promoter usage, and alternative initiation sites of translation. Therefore, the human p53 gene family $(p 53, p 63$, and $p 73$ ) has a dual gene structure. We determined that the dual gene structure is conserved in Drosophila and in zebrafish $p 53$ genes. The conservation through evolution of the dual gene structure suggests that the $\mathrm{p} 53$ isoforms play an important role in p53 tumorsuppressor activity.

We and others have established that the p53 isoforms can regulate cell-fate outcome in response to stress, by modulating p53 transcriptional activity in a promoter and stressdependent manner. We have also shown that the p53 isoforms are abnormally expressed in several types of human cancers, suggesting that they play an important role in cancer formation. The determination of p53 isoforms' expression may help to link clinical outcome to p53 status and to improve cancer patient treatment.

p 53 was first described in 1979 as a protein that binds to the simian virus (SV40) large T antigen (De Leo et al. 1979; Kress et al. 1979; Lane and Crawford 1979; Linzer and Levine 1979; Melero et al. 1979). The p53 protein is the product of a pivotal tumor-suppressor gene whose inactivation in almost all cancers may not only occur through direct mutation or deletion of the $p 53$ gene itself, but also by disrupting any of the pathways that regulate the $\mathrm{p} 53$ protein (Oren 2003). In response to a myriad of stress signals, the p53 protein is activated and thereafter depending on the tissue type and the extent of the cellular damage, triggers adequate cellular response including cell-cycle arrest and programmed cell death (apoptosis) (Vousden and Lane 2007), thus preventing the multiplication of damaged cells that could lead to cancer

Editors: Arnold J. Levine and David Lane

Additional Perspectives on The p53 Family available at www.cshperspectives.org

Copyright (C) 2010 Cold Spring Harbor Laboratory Press; all rights reserved; doi: 10.1101/cshperspect.a000927

Cite this article as Cold Spring Harb Perspect Biol 2010;2:a000927 
formation. Hence, p53 has been dubbed "the guardian of the genome" (Lane 1992). The exact mechanism by which p53 exerts its biological functions is still unclear. Up until now, its tumor-suppressor functions are mostly explained by its ability to modulate gene expression. Indeed, p53 is a transcription factor that binds directly and specifically as a tetramer to target sequences of DNA through p53-responsive elements (p53REs) (El-Deiry et al. 1992; Funk et al. 1992; Bourdon et al. 1997) to transactivate several genes involved in p53 tumorsuppressor activities such as p21 (El-Deiry et al. 1993) (cell-cycle arrest), Puma (Nakano and Vousden 2001), and Scotin (Bourdon et al. 2002) (apoptosis). Despite many experimental and genetic evidences in animal models or human diseases, it is still difficult to associate p53 status to clinical outcome and cancer treatment, suggesting that essential features of the p53 pathways are still unknown.

Two $p 53$-related genes, $p 63$ and $p 73$, were first identified in 1997 (Kaghad et al. 1997; Yang et al. 1998). These two proteins share significant structural and functional homologies with p53, particularly in the DNA-binding domain. Indeed, they are capable of transactivating p53-responsive genes, causing cell-cycle arrest or apoptosis. Together with $\mathrm{p} 53$, they form a family of transcription factors without being entirely redundant functionally and the primary role of each p53 family member illustrates that each protein has its own unique functions, as revealed by the distinct phenotypes developed by p53, p63, and p73 knockout mice (MurrayZmijewski et al. 2006).

As a matter of fact, the $p 63$ gene expresses at least three alternatively spliced carboxy-terminal isoforms $(\alpha, \beta, \gamma)$. Regarding the $p 73$ gene, at least seven alternatively spliced carboxy-terminal isoforms $(\alpha, \beta, \gamma, \delta, \varepsilon, \zeta, \eta)$ are expressed. Moreover, both $p 63$ and $p 73$ genes can be transcribed from a distal and an internal promoter located in intron-3. The distal promoter leads to the expression of TAp63 and TAp73, respectively, whereas the alternative promoter leads to the expression of isoforms deleted in the amino-terminal domain, $\Delta \mathrm{Np} 63$ and $\Delta \mathrm{Np} 73$, respectively. Altogether, the $p 63$ gene expresses six mRNA variants that encode six different p63 protein isoforms, whereas the p73 gene expresses at least $35 \mathrm{mRNAvariants}$ that can theoretically encode 28 different p73 protein isoforms, with 14 of them being so far described. In regard to the biological activities of the $\mathrm{p} 63$ and p73 isoforms, TAp63 and TAp73 bind to p53REs and induce the expression of p53 target genes through their transactivation domain TA. $\Delta \mathrm{Np} 63$ and $\Delta \mathrm{Np} 73$ isoforms can act in a dominant-negative manner toward p53, TAp63, and TAp73 activities (Melino et al. 2003; Benard et al. 2003). The $\Delta \mathrm{Np} 63$ and $\Delta \mathrm{Np} 73$ isoforms have been also shown to specifically bind to p53REs and directly activate specific target genes (Dohn et al. 2001; Wu et al. 2003; Liu et al. 2004).

\section{THE DUAL GENE STRUCTURE OF THE $p 53$ FAMILY GENE IS CONSERVED THROUGH EVOLUTION}

Mammalian genomes contain three members of the $p 53$ family ( $p 53, p 63$, and $p 73$ ), with only one member being identified in invertebrates, suggesting that the mammalian $p 53$ gene family is derived from the triplication of one ancestral gene (Yang et al. 2002). Because of the dual gene structure and the alternative splicing of the $p 63$ and $p 73$ genes, we raised the question of whether the structure of the p53 gene was more complex than it appeared. Using the GeneRacer PCR technique, which allows specific amplification of only capped mRNA, it was possible to determine the transcription initiation sites of the human $p 53$ gene. Consequently, we described that the human p53 gene contains an internal promoter in intron- 4 , confirming that the $p 53$ gene has a dual gene structure like its homologous genes p63 and p73. Moreover, intron-9 of the p53 mRNA can be spliced in three different ways, leading to the expression of $\mathrm{p} 53$ proteins with different carboxy-terminal domains. The intron2 of human p 53 mRNA can also be alternatively spliced, leading to the expression of $\mathrm{p} 53$ proteins deleted of the first 40 amino acids (Fig. 1A). Altogether, the human $p 53$ gene can express nine different forms of the p53 protein (p53, 
p53 Isoforms

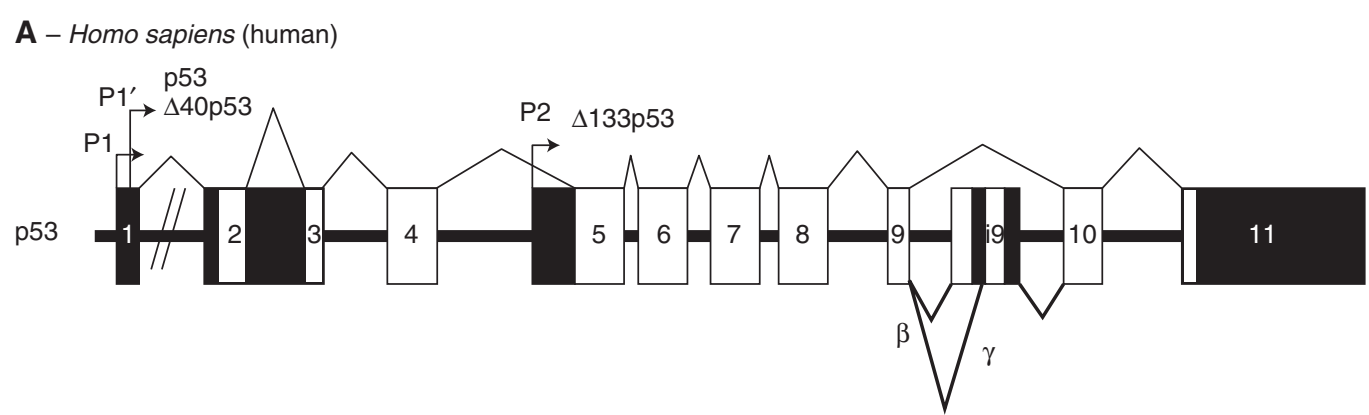

B - Danio rerio (zebrafish)

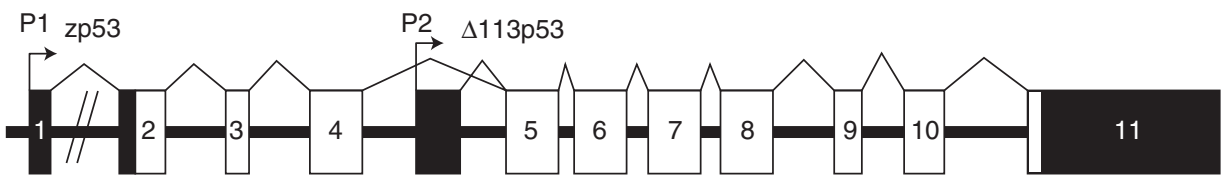

C - Drosophila

dp53

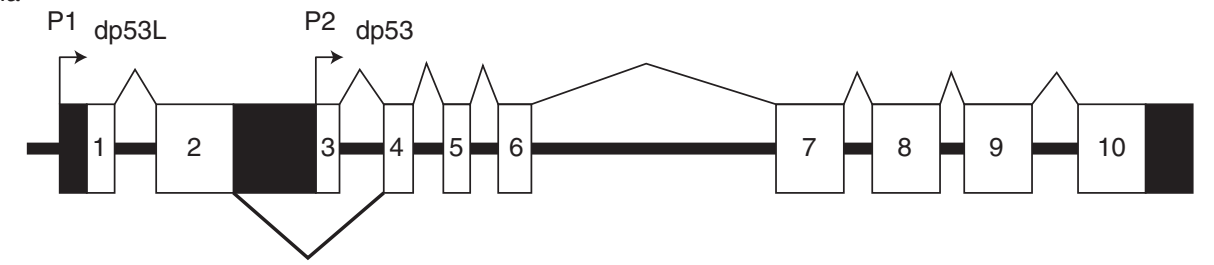

Figure 1. Schema of the 553 genes of (A) Homo sapiens (human), (B) Danio rerio (zebrafish), and (C) Drosophila. Promoters $\left(\mathrm{P} 1, \mathrm{P}^{\prime}\right.$, and $\left.\mathrm{P} 2\right)$ are indicated as $\vdash$. Exons are numbered, noncoding exons are represented by black boxes, and coding exons are represented by white boxes. The size of the boxes is not proportional to the size of the exons. Note: An intraexon splicing of Homo sapien (human) p53 mRNA has been reported through a noncanonical splicing mechanism of the exon-7 to exon-9, leading to a p53 isoform deleted of the conserved box $\mathrm{V}$ in the DNA binding domain $\Delta$ p53 (Rohaly et al. 2005). However, expression of $\Delta$ p53 at the mRNA and protein levels is still controversial and has not been confirmed by other laboratories.

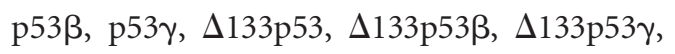
$\Delta 40 \mathrm{p} 53, \Delta 40 \mathrm{p} 53 \beta$, and $\Delta 40 \mathrm{p} 53 \gamma$ ), containing different domains of the protein because of alternative splicing, alternative promoter usage, and alternative initiation of translation (Fig. 2A) (Bourdon et al. 2005).

To determine whether the dual $p 53$ gene structure is conserved through evolution, we examined the expression pattern of the Drosophila p53 gene by Generacer PCR on total RNA extracted from Drosophila embryos (Fig. 1C). We then identified three variants of Drosophila p53 mRNA (Fig. 2C). The first variant encodes the dp53L protein 495 (aa) with a large aminoterminal domain containing the transactivation domain Fxx $\psi \mathrm{W}$ conserved in 553 proteins of mammals, birds, amphibians, fish, and mollusks. The conservation of the transactivation domain Fxx $\psi$ W defines the dp53L protein as homologous to full-length p53 (FLp53), TAp63, and TAp73 proteins. The second mRNA variant $(\mathrm{dp} 53 \mathrm{n})$ is a splice variant of $\mathrm{dp} 53 \mathrm{~L}$, retaining intron- 2 and encoding only the first 123 amino acids (dp53n). The third variant (dp53) previously described (Brodsky et al. 2000; Jin et al. 2000; Ollmann et al. 2000) is obtained from an internal promoter located upstream of exon-3 (previously designated as exon-1) and encodes the dp53 protein 385 (aa) deleted of the first 123 aa. Hence, the dp53 protein is an amino terminally truncated isoform produced from an internal promoter, confirming that the dual gene structure of the 
M.P. Khoury and J.-C. Bourdon

A - Homo sapien (human) p53 protein isoforms
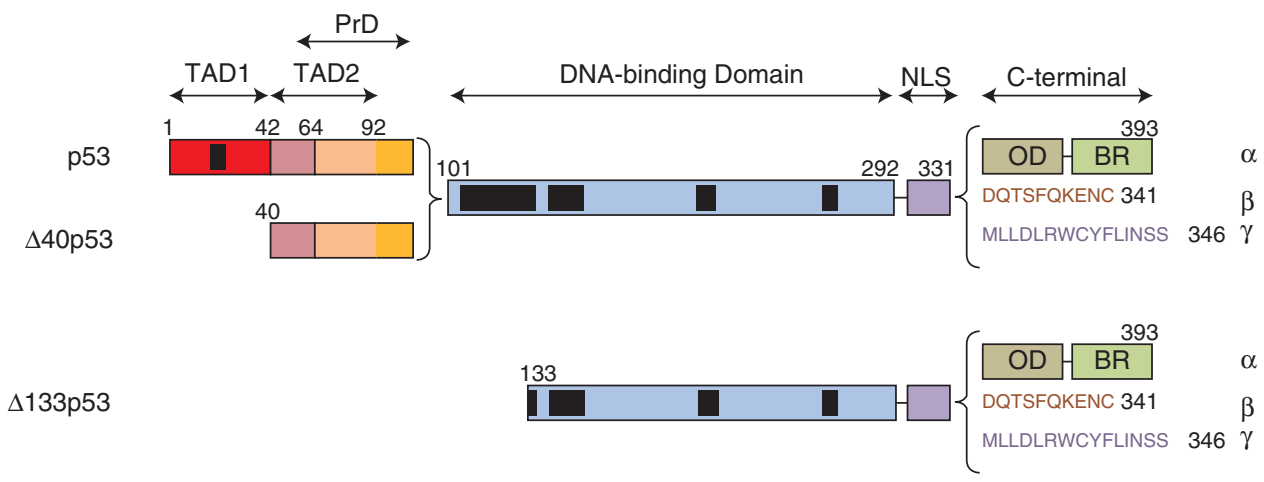

B - Danio rerio (zebrafish) p53 protein isoforms

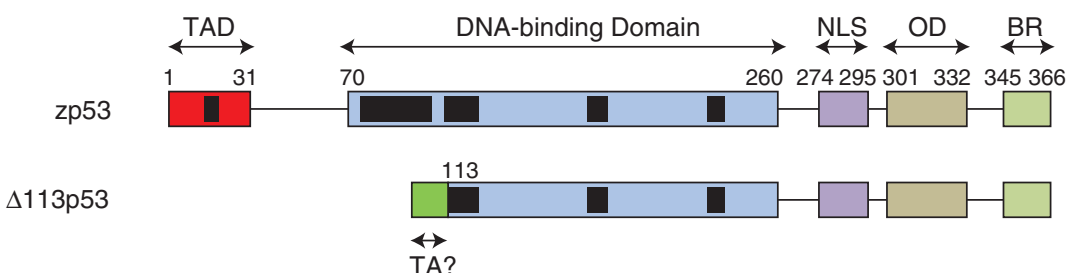

C - Drosophila p53 protein isoforms

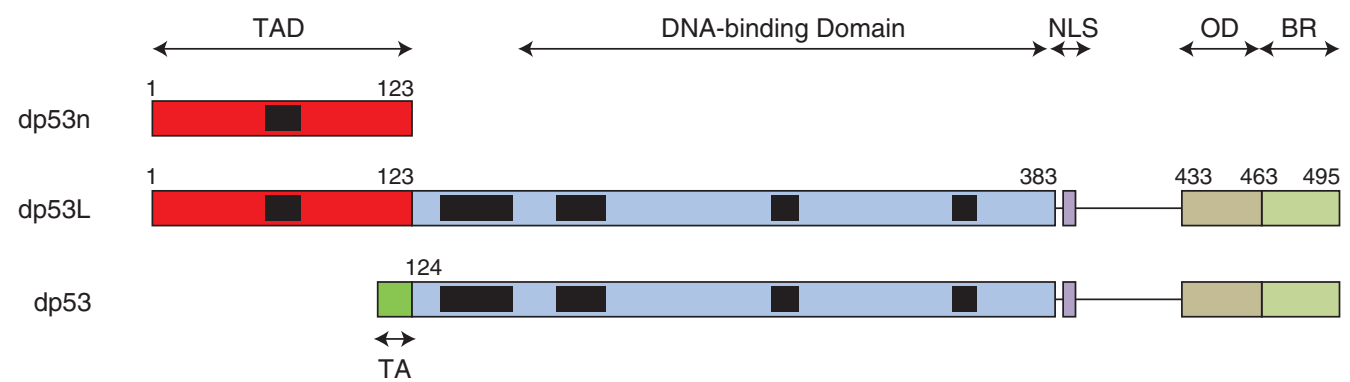

Figure 2. Schema of the p53 isoform proteins encoded by Homo sapiens (human) (A), Danio rerio (zebrafish) $(B)$, and Drosophila $(C)$ p53 genes. (TAD) transactivation domain (TAD1 and TAD2); (PrD) proline domain; (NLS) nuclear localization signal; (OD) oligomerization domain; (BR) basic region. The black boxes represent amino-acid domains conserved through evolution. The amino-acid positions defining p53 domains are indicated. Carboxy-terminal amino-acid sequences of Homo sapien (human) p $53 \beta$ and p53 $\gamma$ are indicated. p53 domains for Drosophila p53 are based on protein alignment and need to be confirmed by experimental evidence.

p53 gene is conserved in Drosophila (Bourdon et al. 2005).

Moreover, Chen et al. have established that the zebrafish $p 53$ gene contains an internal promoter (Fig. 1B), encoding an amino terminally truncated protein $(\Delta 113 \mathrm{p} 53)$ initiated at codon
113 and homologous to human $\Delta 133$ p53 (Fig. 2B), confirming that the dual gene structure of the $p 53$ gene is conserved through evolution and suggesting that the internal promoter plays an essential role in $p 53$ gene family activities (Chen et al. 2005; Chen et al. 2009). 
p53 Isoforms

\section{ANTIBODIES FOR THE p53 ISOFORMS}

To determine the biological activities of the human $\mathrm{p} 53$ isoforms, we assessed the specificity of the currently commercially available antibodies for the p53 protein. Table 1 shows the antibodies that we have experimentally tested. As shown in Figure 3, some of the antibodies are either pantropic or recognize only a subset of the p53 isoforms. The mouse monoclonal antibodies DO-1 and DO-7, which share the same epitope, are only specific for FLp53, p53 3 , and p53 $\gamma$. Additionally, the mouse monoclonal antibody 1801 allows the detection of all p53 isoforms except $\Delta 133 \mathrm{p} 53(\alpha, \beta$, and $\gamma)$, whereas the mouse monoclonal DO-12 is pantropic, because its epitope, localized in the DNA-binding domain (DBD), is common for all of the p53 isoforms. Moreover, the mouse monoclonal antibodies BP53.10, 421, and ICA-9 are specific for the $\alpha$ isoforms of p53 (FLp53, $\Delta 40 \mathrm{p} 53 \alpha$, and $\Delta 133 \mathrm{p} 53 \alpha$ ), because their epitopes are localized in the basic region (BR) of the p53 protein.

The polyclonal rabbit CM-1 and sheep SAPU antibodies, both raised against recombinant human FLp53, can detect all p53 isoforms. However, CM-1 poorly detects $\Delta 133 \mathrm{p} 53 \beta$ and $\Delta 133 \mathrm{p} 53 \gamma$, as its epitopes are localized in the amino and carboxyl terminus of FLp53. The SAPU antibody has an additional epitope in the DBD, allowing it to detect efficiently all p53 isoforms. However, as the p53 isoforms do not contain all the epitopes of CM-1 and SAPU, it is difficult to assess their relative expression using these antibodies. Only the DO-12 antibody would allow such comparison.

As none of the commercially available antibodies listed previously are capable of identifying specifically each p53 isoform, we raised two novel rabbit polyclonal antibodies, KJC8 and MAP4.9 specific, respectively, for the $\beta$ isoforms of p53 and the $\Delta 133 \mathrm{p} 53$ isoforms.

\section{BIOLOGICAL AND MOLECULAR ACTIVITIES OF THE p53ß AND $\Delta$ 133p53 ISOFORMS}

We were able to show by chromatin-immunoprecipitation (ChIP assay) using the KJC8 antibody and MCF7 cells extract, that endogenous p53 $\beta$ can bind specifically to p53-responsive promoters in a promoter-dependent manner. p53 $\beta$ preferentially binds to the Bax promoter (a proapoptotic gene), but poorly to the $M d m 2$ promoter (a ubiquitin ligase of the p53 protein), whereas FLp53 preferentially binds to the $M d m 2$ promoter but poorly to the Bax promoter (Bourdon et al. 2005). By luciferase assay, we determined that p53 $\beta$ enhances p53 transcriptional activity on the Bax promoter but has no effect on the $p 21$ promoter. This effect can be caused by a direct interaction of p53 $\beta$ with p53, because endogenous p53 $\beta$ can form a protein complex with FLp53. However, we and others were unable to coimmunoprecipitate p53 $\beta$ with p53 after transient transfection, suggesting that the interaction between p53 and p53 $\beta$ could involve other protein(s). Recently, we reported that $\mathrm{p} 53 \beta$ promotes

Table 1. Summary of the p53 antibodies recognizing the p53 isoforms

\begin{tabular}{|c|c|c|c|c|c|c|c|c|c|c|c|}
\hline & DO-1 & DO-7 & 1801 & DO-12 & BP53.10 & 421 & ICA-9 & KJC8 & MAP4.9 & CM-1 & SAPU \\
\hline p53 $\Delta$ FLp53) & ++ & ++ & + & + & + & + & + & - & - & ++ & ++ \\
\hline p $53 \beta$ & ++ & ++ & + & + & - & - & - & + & - & ++ & ++ \\
\hline $\mathrm{p} 53 \gamma$ & ++ & ++ & + & + & - & - & - & - & - & ++ & ++ \\
\hline$\Delta 40 \mathrm{p} 53 \alpha$ & - & - & + & + & + & + & + & - & - & ++ & ++ \\
\hline$\Delta 40 \mathrm{p} 53 \beta$ & - & - & + & + & - & - & - & + & - & + & ++ \\
\hline$\Delta 40 \mathrm{p} 53 \gamma$ & - & - & + & + & - & - & - & - & - & + & ++ \\
\hline$\Delta 133 \mathrm{p} 53 \alpha$ & - & - & - & + & + & + & + & - & + & + & + \\
\hline$\Delta 133 \mathrm{p} 53 \beta$ & - & - & - & + & - & - & - & + & + & $+/-$ & + \\
\hline$\Delta 133 \mathrm{p} 53 \gamma$ & - & - & - & + & - & - & - & - & + & $+/-$ & + \\
\hline
\end{tabular}

Each antibody has been assessed by Western blotting.

++ : strong detection, + : detection, $+/-$ : weak detection, - : no detection. 
M.P. Khoury and J.-C. Bourdon

A - Epitope map for commercially available p53 antibodies

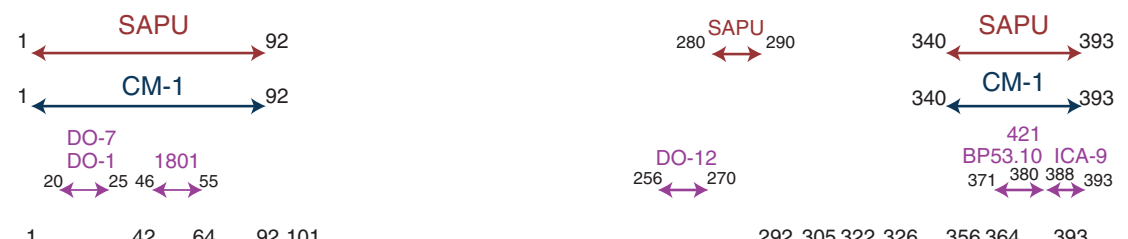

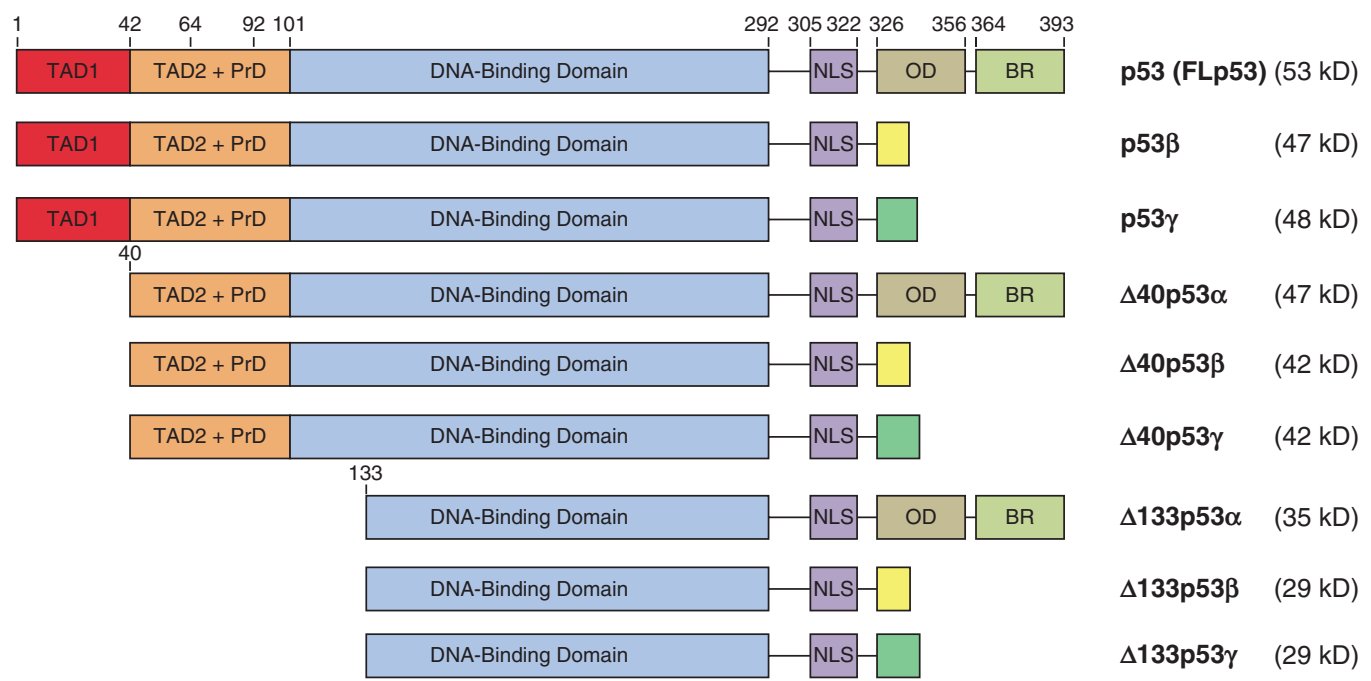

B - $\boldsymbol{\beta}$ isoforms of $\mathrm{p} 53$ specifically recognized by the KJC8 antibody

KJC8

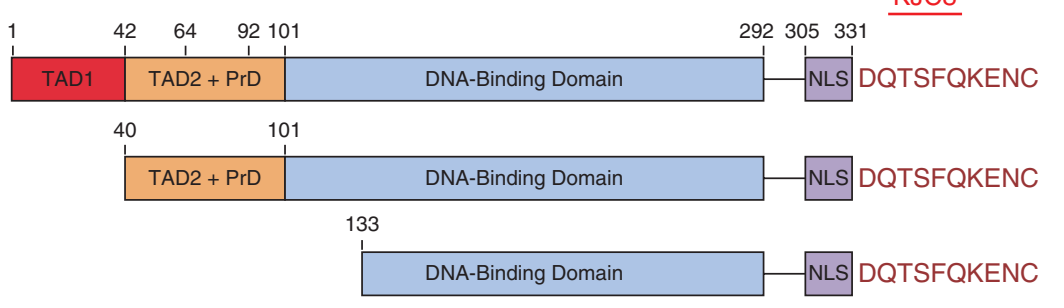

p53ß

$(47 \mathrm{kD})$

$\Delta 40 \mathrm{p} 53 \beta \quad(42 \mathrm{kD})$

$\Delta 133 p 53 \beta \quad(29 \mathrm{kD})$

C - $\Delta 133 p 53$ isoforms specifically recognized by the MAP4.9 antibody

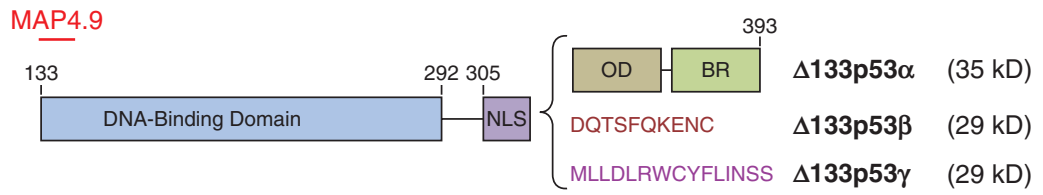

Figure 3. Regions of Homo sapien (human) p53 protein isoforms specifically recognized by p53 antibodies. $(A)$ Epitope map for commercially available p53 antibodies. Epitopes of the mouse monoclonal antibodies DO-1, DO-7, 1801, DO-12, BP53.10, 421, and ICA-9 are indicated in violet, epitopes of the rabbit polyclonal antibody CM-1 raised against full-length recombinant Homo sapien (human) p53 protein are indicated in blue, and epitopes of the sheep polyclonal antibody SAPU raised against full-length recombinant Homo sapien (human) p53 protein are indicated in brown. (TAD) transactivation domain; (PrD) proline domain; (NLS) nuclear localization signal; (OD) oligomerization domain; (BR) basic region. The amino-acid positions defining p53 domain are indicated. The carboxy-terminal domains of p53 $\beta$ and p $53 \gamma$ are indicated with a yellow and green box, respectively. The molecular weight of each Homo sapien (human) p53 isoform is indicated $(\mathrm{kDa}) .(B, C)$ p53 isoforms specifically recognized by the rabbit polyclonal antibodies specific for $\beta$ isoforms (KJC8) and $\Delta 133$ p53 isoforms (MAP4.9), respectively. 
replicative cellular senescence when coexpressed with FLp53 in normal human fibroblasts by increasing p53-dependent induction of p21 expression (Fujita et al. 2009). Altogether, the results suggest that $\mathrm{p} 53 \beta$ is a modulator of $\mathrm{p} 53$ tumor-suppressor activity by modulating p53 transcriptional activity and thus switching cell fate outcome.

Regarding the $\Delta 133$ p53 isoform, we have shown that ectopic expression of $\Delta 133$ p53 inhibits p53-mediated apoptosis after transient transfection in H1299 cells. By luciferase assay, we determined that co-transfection of $\Delta 133 \mathrm{p} 53$ isoform with FLp53 inhibits p53 transcriptional activity on the Bax promoter and $p 21$ promoter. Furthermore, we established by coimmunoprecipitation assay that $\Delta 133 \mathrm{p} 53$ can form a protein complex with FLp53. Therefore, it is likely that $\Delta 133 \mathrm{p} 53$ inhibits $\mathrm{p} 53$ transcriptional activity by direct interaction with FLp53. Consistent with this, we recently reported that expression of $\Delta 133$ p53 isoform inhibits replicative senescence and promotes cellular proliferation of normal human fibroblasts by modulating p53 transcriptional activity (Fujita et al. 2009). To determine the biological activity of $\Delta 133$ p53 at physiological level, we took advantage of the zebrafish animal model and established that $\Delta 113 \mathrm{p} 53$, the zebrafish counterpart of human $\Delta 133 \mathrm{p} 53$, is induced in a p53-dependent manner in response to embryo development defects or ionizing radiation. Importantly, specific repression of endogenous $\Delta 113 \mathrm{p} 53$ by injection of morpholino RNA into zebrafish embryos sensitizes embryos to p53-mediated apoptosis, promoted by ionizing radiation or embryo development defects. Interestingly, injection of $\Delta 113$ p53 mRNA into zebrafish embryos modulates p53-transcriptional activity and prevents apoptosis by inducing BclxL expression, suggesting that $\Delta 113 \mathrm{p} 53$ does not act exclusively in a dominant-negative manner toward p53 but rather modulates p 53 target gene expression in a promoter and stress-dependent manner (Chen et al. 2005; Chen et al. 2009).

Altogether, the results clearly show that the $\Delta 113$ p53 isoform has a biological relevance at physiological level in zebrafish embryos by preventing p53-mediated apoptosis. However, it remains to be investigated whether human $\Delta 133$ p53 has a biological relevance at physiological level in mammalian animal models and in human cells.

Based on the current data, we propose that some p53 isoforms can modulate p53 transcriptional activity. However, it is worth noting that the p53 isoforms may have biological activities independent of p53 and also that they may be involved in p53-dependent but transcriptionally independent activities. Further investigation will be required to decipher p53 isoforms' biological and biochemical activities.

\section{REGULATION OF p53 ISOFORMS' EXPRESSION}

The human p53 splice variants and the internal promoter-initiated products are expressed in a wide range of normal tissues in a tissue-dependent manner, suggesting that the internal promoter and the splicing of p53 can be regulated. Moreover, p53 protein isoforms have different subcellular localizations, suggesting that each p53 isoform can have different biological activities (Bourdon et al. 2005). Immunofluorescence experiments of the p53 isoforms revealed that $\Delta 133 \mathrm{p} 53$ and $\mathrm{p} 53 \beta$ are mainly localized in the nucleus with a minor staining in the cytoplasm. Additionally, p53 $\gamma$ was found to be localized in the nucleus in most cells and in the cytoplasm in some others, suggesting that p53 $\gamma$ could be shuttling between the nucleus and the cytoplasm and that its subcellular localization can be regulated. Furthermore, $\Delta 133$ p $53 \beta$ protein was seen in the nucleus and the cytoplasm in most cells, with $10 \%$ of cells revealing the formation of $\Delta 133 \mathrm{p} 53 \beta$ foci in the nucleus. Interestingly, whereas $\Delta 133 \mathrm{p} 53 \beta$ and $\Delta 133$ p $53 \gamma$ isoforms differ only by the last 15 carboxy-terminal amino acids, $\Delta 133 \mathrm{p} 53 \gamma$ is exclusively localized in the cytoplasm, indicating that the carboxy-terminal amino acids can modify the subcellular localization of these isoforms.

Altogether, the results suggest that the activities of the p53 isoforms can be regulated by altering the p53 internal promoter activity, the splicing of p53 mRNA, and the subcellular localization of the p53 isoforms. 
M.P. Khoury and J.-C. Bourdon

\section{THE p53 ISOFORMS AND CANCER}

In light of these results, we and others have analyzed the expression of the p53 isoforms in different types of human breast cancer, acute myeloid leukemia (AML), head and neck tumors (SCCHN), melanoma, ovarian tumors, renal cell carcinoma, and colon tumors (Bourdon et al. 2005; Anensen et al. 2006; Boldrup et al. 2007; Avery-Kiejda et al. 2008; Marabese et al. 2008; Song et al. 2009). Abnormal expression of the p53 isoforms has been reported in head and neck tumors as well as in ovarian tumors (Boldrup et al. 2007; Marabese et al. 2008). Concerning breast tissue, normal breast tissue expresses p53, p53 $\beta$, and p53 $\gamma$ but not the other p53 isoforms. Only $25 \%$ of tumors present a mutation of the $p 53$ gene, suggesting that $\mathrm{p} 53$ and its pathway are inactivated by other mechanisms. We reported in 30 randomly selected primary breast tumors that $60 \%$ of the cases have lost the expression of p $53 \beta$ and p $53 \gamma$, whereas $40 \%$ of them have gained the expression of $\Delta 133 \mathrm{p} 53$. Importantly, the p53 isoforms are differentially expressed compared with normal breast tissue and from tumor to tumor (Bourdon et al. 2005). Further clinical studies on a larger number of breast tumors will be necessary to determine the association of the expression of the p53 isoforms with clinical outcome and clinical markers. However, as the p53 isoforms can inhibit or enhance p53 tumor-suppressor activity, it suggests that abnormal expression of the p53 isoforms can account for a loss of p53 tumor-suppressor activity in breast tumors.

In AML, only $10 \%$ of the cases present a mutation of the $p 53$ gene, suggesting here also that p53 tumor-suppressor activity is inhibited by other mechanisms. Anensen et al. reported an abnormal expression of the p53 isoforms, both at the mRNA and the protein levels in AML (Anensen et al. 2006). In their report, they described a rapid shift from short forms toward long forms of $\mathrm{p} 53$ proteins in blood samples of AML patients within 4 hours of chemotherapy, using RT-PCR and two-dimensional immunoblots. This observation indicates that the expression of the p53 protein isoforms could be modulated in vivo in response to chemotherapy. Moreover, they noticed that the expression of the p53 protein isoforms did not change in response to chemotherapy in patients who did not respond to treatment, suggesting that the 533 isoforms could be associated with AML patient survival. The analysis of the expression of the p53 isoforms in relation to patient survival should be performed on a larger cohort of AML patients from several hospitals to confirm this hypothesis.

In melanoma cell lines and primary tumors, p $53 \beta$ and $\Delta 40 \mathrm{p} 53$ were reported to be expressed at the mRNA level in the majority of melanoma cell lines but were undetectable in fibroblasts and melanocytes, suggesting that they can play a role in melanoma development (AveryKiejda et al. 2008). Additionally, p53 $\beta$ and other short forms of p53 could be detected at the protein level by Western blot in several melanoma cell lines. The authors reported that the p53 isoforms are differentially localized in the melanoma cell nucleus and the cytosol in a cell-linedependent manner and that the protein expression levels of the p53 isoforms could be modulated in response to cisplatin treatment. This could explain the differences in the expression of p53 target genes in melanoma cell lines in response to cisplatin.

Another recent report analyzed the patterns of expression of the p53 isoforms in renal cell carcinoma (RCC), both at the mRNA and protein levels in relation to clinical markers (Song et al. 2009). The specimens of tumor and clinically normal tissue adjacent to them were collected from 41 patients with RCC. p53 isoform mRNA were detected by RT-PCR followed by nested PCR and protein expression levels were analyzed by immunohistochemisty and Western blotting. All p53 isoforms (p53, p53 3 ,

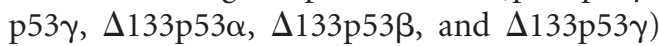
could be detected in tumors and normal tissue, with the exception of the $\Delta 133 \mathrm{p} 53 \beta$ isoform, which was not detected in normal tissue. Although nested PCR results consistently revealed the expression of $\mathrm{p} 53 \gamma, \Delta 133 \mathrm{p} 53 \alpha$, $\Delta 133 \mathrm{p} 53 \beta$, and $\Delta 133 \mathrm{p} 53 \gamma$ in tumors, only p $53 \beta$ mRNA was significantly overexpressed in tumor samples, and was associated with tumor stage, suggesting that $\mathrm{p} 53 \beta$ plays an important 
role in the formation of RCC and can be used as a new biomarker for RCC. Moreover, as all p53 isoforms are differentially expressed in RCC, it suggests that their function in tumor development or progression might be different.

Furthermore, Fujita et al. have recently investigated the role of endogenous $\Delta 133 \mathrm{p} 53$ and p53 $\beta$ on replicative senescence (Fujita et al. 2009). They determined that $\Delta 133 \mathrm{p} 53$ inhibits senescence, whereas p $53 \beta$ promotes senescence in normal human fibroblasts. They analyzed the expression of $\Delta 133 \mathrm{p} 53$ and $\mathrm{p} 53 \beta$ in a cohort of colon adenomas and carcinomas. They reported that the colon adenoma with senescent phenotype is associated in vivo with the expression pattern of the p53 isoforms. However, the increased $\Delta 133 \mathrm{p} 53$ and decreased $\mathrm{p} 53 \beta$ isoform expression found in colon carcinomas may signal an escape from the senescence barrier during the progression from adenoma to carcinoma.

In conclusion, many clinical studies report the expression of the p53 isoforms in several types of cancer, confirming that the p53 isoforms are expressed both at the mRNA and protein levels. Moreover, the abnormal expression of the p53 isoforms in different cancer types suggests that their differential expression may disrupt the p53 response and contribute to tumor formation. Furthermore, it may provide an explanation to the difficulties in many clinical studies to link p53 status to cancer prognosis and treatment.

\section{ACKNOWLEDGMENTS}

Marie P. Khoury is supported by Inserm (Institut National de la Santé Et de la Recherche Médicale) and Jean-Christophe Bourdon is supported by Cancer-Research UK. The authors wish to thank Drs. Mark Saville and Kenneth Fernandes for their constructive discussions.

\section{REFERENCES}

Anensen N, Oyan AM, Bourdon JC, Kalland KH, Bruserud O, Gjertsen BT. 2006. A distinct p53 protein isoform signature reflects the onset of induction chemotherapy for acute myeloid leukemia. Clin Cancer Res 12: 3985-3992.
Avery-Kiejda KA, Zhang XD, Adams LJ, Scott RJ, Vojtesek B, Lane DP, Hersey P. 2008. Small molecular weight variants of p53 are expressed in human melanoma cells and are induced by the DNA-damaging agent cisplatin. Clin Cancer Res 14: 1659-1668. Epub 2008 Feb 1629.

Bénard J, Douc-Rasy S, Ahomadegbe JC. 2003. TP53 family members and human cancers. Hum Mutat 21: 182-191.

Boldrup L, Bourdon JC, Coates PJ, Sjostrom B, Nylander K. 2007. Expression of p53 isoforms in squamous cell carcinoma of the head and neck. Eur J Cancer 43: 617-623.

Bourdon JC, Deguin-Chambon V, Lelong JC, Dessen P, May P, Debuire B, May E. 1997. Further characterisation of the $\mathrm{p} 53$ responsive element-identification of new candidate genes for trans-activation by p53. Oncogene 14: 85-94.

Bourdon JC, Fernandes K, Murray-Zmijewski F, Liu G, Diot A, Xirodimas DP, Saville MK, Lane DP. 2005. p53 isoforms can regulate p53 transcriptional activity. Genes Dev 19: 2122-2137.

Bourdon JC, Renzing J, Robertson PL, Fernandes KN, Lane DP. 2002. Scotin, a novel p53-inducible proapoptotic protein located in the ER and the nuclear membrane. J Cell Biol 158: 235-246.

Brodsky MH, Nordstrom W, Tsang G, Kwan E, Rubin GM, Abrams JM. 2000. Drosophila p53 binds a damage response element at the reaper locus. Cell 101: 103-113.

Chen J, Ng SM, Chang C, Zhang Z, Bourdon JC, Lane DP, Peng J. 2009. p53 isoform $\Delta 113$ p53 is a p53 target gene that antagonizes p53 apoptotic activity via BclxL activation in zebrafish. Genes Dev 23: 278-290.

Chen J, Ruan H, Ng SM, Gao C, Soo HM, Wu W, Zhang Z, Wen Z, Lane DP, Peng J. 2005. Loss of function of def selectively up-regulates $\Delta 113 \mathrm{p} 53$ expression to arrest expansion growth of digestive organs in zebrafish. Genes Dev 19: 2900-2911.

De Leo AB, Jay G, Appella E, Dubois GC, Law LW, Old LJ. 1979. Detection of a transformation-related antigen in chemically induced sarcomas and other transformed cells of the mouse. Proc Natl Acad Sci 76: 2420-2424.

Dohn M, Zhang S, Chen X. 2001. p63 $\alpha$ and $\Delta$ Np63 $\alpha$ can induce cell cycle arrest and apoptosis and differentially regulate p53 target genes. Oncogene 20: 3193-3205.

El-Deiry WS, Kern SE, Pietenpol JA, Kinzler KW, Vogelstein B. 1992. Definition of a consensus binding site for p53. Nat Genet 1: 45-49.

El-Deiry WS, Tokino T, Velculescu VE, Levy DB, Parsons R, Trent JM, Lin D, Mercer WE, Kinzler KW, Vogelstein B. 1993. WAF1, a potential mediator of p53 tumor suppression. Cell 75: 817-825.

Fujita K, Mondal AM, Horikawa I, Nguyen GH, Kumamoto K, Sohn JJ, Bowman ED, Mathe EA, Schetter AJ, Pine SR, et al. 2009. p53 isoforms, $\Delta 133 \mathrm{p} 53$ and p53 $\beta$, are endogenous regulators of replicative cellular senescence. Nat Cell Biol 11: 1135-1142.

Funk WD, Pak DT, Karas RH, Wright WE, Shay JW. 1992. A transcriptionally active DNA-binding site for human p53 protein complexes. Mol Cell Biol 12: 2866-2871.

Jin S, Martinek S, Joo WS, Wortman JR, Mirkovic N, Sali A, Yandell MD, Pavletich NP, Young MW, Levine AJ. 2000. Identification and characterization of a p53 homologue 
M.P. Khoury and J.-C. Bourdon

in Drosophila melanogaster. Proc Natl Acad Sci 97: 7301-7306.

Kaghad M, Bonnet H, Yang A, Creancier L, Biscan JC, Valent A, Minty A, Chalon P, Lelias JM, Dumont X et al. 1997. Monoallelically expressed gene related to p53 at 1 p36, a region frequently deleted in neuroblastoma and other human cancers. Cell 90: 809-819.

Kress M, May E, Cassingena R, May P. 1979. Simian virus 40-transformed cells express new species of proteins precipitable by anti-simian virus 40 tumor serum. J Virol 31: 472-483.

Lane DP. 1992. Cancer. p53, guardian of the genome [news; comment] [see comments]. Nature 358: 15-16.

Lane DP, Crawford LV. 1979. T antigen is bound to a host protein in SV40-transformed cells. Nature 278: 261-263.

Linzer DIH, Levine AJ. 1979. Characterization of a $54 \mathrm{~K}$ dalton cellular SV40 tumor antigen present in SV40-transformed cells and in infected embryonal carcinoma cells. Cell 1: 43-52.

Liu G, Nozell S, Xiao H, Chen X. 2004. $\Delta$ Np73 $\beta$ is active in transactivation and growth suppression. Mol Cell Biol 24: 487-501.

Marabese M, Marchini S, Marrazzo E, Mariani P, Cattaneo D, Fossati R, Compagnoni A, Signorelli M, Moll UM, Codegoni AM et al. 2008. Expression levels of p53 and p73 isoforms in stage I and stage III ovarian cancer. Eur J Cancer 44: 131-141.

Melero JA, Stitt DT, Mangel WF, Carroll RB. 1979. Identification of new polypeptide species $48-55 \mathrm{~K}$ ) immunoprecipitable by antiserum to purified large $\mathrm{T}$ antigen and present in simian virus 40-infected and transformed cells. J Virol 93: 466-480.

Melino G, Lu X, Gasco M, Crook T, Knight RA. 2003. Functional regulation of $\mathrm{p} 73$ and p63: development and cancer. Trends Biochem Sci 28: 663-670.
Murray-Zmijewski F, Lane DP, Bourdon JC. 2006. p53/p63/ p73 isoforms: An orchestra of isoforms to harmonise cell differentiation and response to stress. Cell Death Differ 13: $962-972$.

Nakano K, Vousden KH. 2001. PUMA, a novel proapoptotic gene, is induced by p53. Mol Cell 7: 683-694.

Ollmann M, Young LM, Di Como CJ, Karim F, Belvin M, Robertson S, Whittaker K, Demsky M, Fisher WW, Buchman A et al. 2000. Drosophila p53 is a structural and functional homolog of the tumor suppressor p53. Cell 101: $91-101$.

Oren M. 2003. Decision making by p53: Life, death and cancer. Cell Death Differ 10: 431-442.

Rohaly G, Chemnitz J, Dehde S, Nunez AM, Heukeshoven J, Deppert W, Dornreiter I. 2005. A novel human p53 isoform is an essential element of the ATR-intra-S phase checkpoint. Cell 122: 21-32.

Song W, Huo SW, Lu JJ, Liu Z, Fang XL, Jin XB, Yuan MZ. 2009. Expression of p53 isoforms in renal cell carcinoma. Chin Med J Engl 122: 921-926.

Vousden KH, Lane DP. 2007. p53 in health and disease. Nat Rev Mol Cell Biol 8: 275-283.

Wu G, Nomoto S, Hoque MO, Dracheva T, Osada M, Lee CC, Dong SM, Guo Z, Benoit N, Cohen Y et al. 2003. $\Delta \mathrm{Np} 63 \alpha$ and TAp63 $\alpha$ regulate transcription of genes with distinct biological functions in cancer and development. Cancer Res 63: 2351-2357.

Yang A, Kaghad M, Wang Y, Gillett E, Fleming MD, Dotsch V, Andrews NC, Caput D, McKeon F. 1998. p63, a p53 homolog at 3q27-29, encodes multiple products with transactivating, death-inducing, and dominant-negative activities. Mol Cell 2: 305-316.

Yang A, Kaghad M, Caput D, McKeon F. 2002. On the shoulders of giants: p63, p73 and the rise of p53. Trends Genet 18: 90-95. 


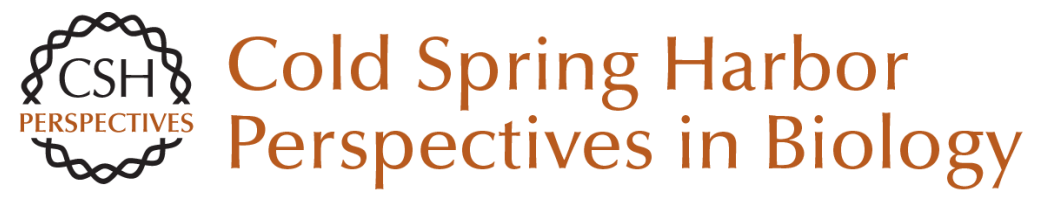

\section{The Isoforms of the p53 Protein}

Marie P. Khoury and Jean-Christophe Bourdon

Cold Spring Harb Perspect Biol 2010; doi: 10.1101/cshperspect.a000927 originally published online November 25, 2009

\section{Subject Collection The p53 Family}

The Origins and Evolution of the p53 Family of Genes

Vladimir A. Belyi, Prashanth Ak, Elke Markert, et al.

Mouse Models of p53 Functions Guillermina Lozano

TP53 Mutations in Human Cancers: Origins, Consequences, and Clinical Use

Magali Olivier, Monica Hollstein and Pierre Hainaut

p53 Research: The Past Thirty Years and the Next Thirty Years

David Lane and Arnold Levine

Transcriptional Regulation by P53

Rachel Beckerman and Carol Prives

p53-based Cancer Therapy

David P. Lane, Chit Fang Cheok and Sonia Lain

Phylogeny and Function of the Invertebrate p53

Superfamily

Rachael Rutkowski, Kay Hofmann and Anton Gartner

Tied Up in Loops: Positive and Negative

Autoregulation of p53

Xin Lu
The Tumor Suppressor p53: From Structures to

Drug Discovery

Andreas C. Joerger and Alan R. Fersht

p53 Regulation of Metabolic Pathways

Eyal Gottlieb and Karen H. Vousden

The Regulation of the p53-mediated Stress

Response by MDM2 and MDM4 Mary Ellen Perry

Zebrafish Models of p53 Functions Narie Y. Storer and Leonard I. Zon

p63 and p73, the Ancestors of p53

V. Dötsch, F. Bernassola, D. Coutandin, et al.

Pathologies Associated with the p53 Response Andrei V. Gudkov and Elena A. Komarova

Single-nucleotide Polymorphisms in the p53

Signaling Pathway

Lukasz F. Grochola, Jorge Zeron-Medina, Sophie Mériaux, et al.

Clinical Outcomes and Correlates of TP53

Mutations and Cancer

Ana I. Robles and Curtis C. Harris

For additional articles in this collection, see http://cshperspectives.cshlp.org/cgi/collection/

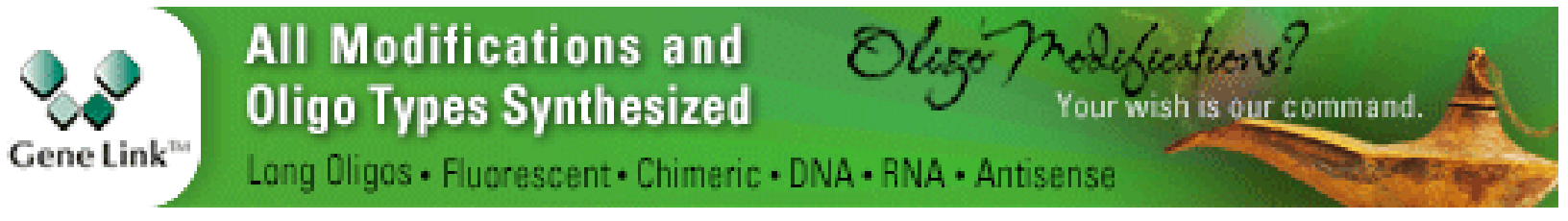

Copyright (C 2010 Cold Spring Harbor Laboratory Press; all rights reserved 